REGARDS

SUR L'ECONOMIE ALLEMANDE

BULLETIN ECONOMIQUE DUCIRAC

\section{Regards sur l'économie allemande}

Bulletin économique du CIRAC

$77 \mid 2006$

Varia

\title{
Une nouvelle Allemagne
}

MATUSSEK Matthias, Wir Deutschen. Warum uns die anderen gern haben können / HANKE Thomas, Der neue deutsche Kapitalismus. Republik im Wandel

\section{(2) OpenEdition}

12 Journals

Édition électronique

URL : http://journals.openedition.org/rea/475

DOI : $10.4000 /$ rea. 475

ISBN : 978-2-8218-0850-8

ISSN : 1965-0787

Éditeur

CIRAC

Édition imprimée

Date de publication : 1 juillet 2006

ISSN : 1156-8992

Référence électronique

"Une nouvelle Allemagne », Regards sur l'économie allemande [En ligne], 77 | juillet 2006, document 1, mis en ligne le 24 avril 2008, consulté le 22 septembre 2020. URL : http://journals.openedition.org/rea/ 475 ; DOl : https://doi.org/10.4000/rea.475

Ce document a été généré automatiquement le 22 septembre 2020.

(c) CIRAC 


\section{Une nouvelle Allemagne}

MATUSSEK Matthias, Wir Deutschen. Warum uns die anderen gern haben können / HANKE Thomas, Der neue deutsche Kapitalismus. Republik im Wandel

\section{RÉFÉRENCE}

MATUSSEK Matthias, Wir Deutschen. Warum uns die anderen gern haben können, S. Fischer Verlag, Francfort, 2006, 352 p.

HANKE Thomas, Der neue deutsche Kapitalismus. Republik im Wandel, Campus

Verlag, Francfort/New York, 2006, 230 p.

1 En ces semaines de Mondial de football, les Allemands redécouvrent les valeurs du patriotisme. "Ils en avaient oublié jusqu'à la notion même " après la catastrophe nazie, et même la joie de voir tomber le Mur, la perspective d'être enfin réunis, leur semblaient suspectes, ne leur laissant le choix que d'ancrer leur identité dans une entité supranationale : l'Europe, et de construire leur quête collective de valeurs identitaires sur une logique de performance et de compétitivité à l'échelle du marché mondial. Certes, ils se reconnaissent toujours dans leur Constitution et ses principes éthiques qui fondent l'organisation de leur société. Mais ce renouveau au sortir de la guerre les avait aussi coupés de leur patrimoine. Le devoir de mémoire, concentré sur 13 années, avait occulté la mémoire d'une histoire millénaire, transformant les Allemands littéralement en "analphabètes» de leur riche culture, ce qui leur interdisait tout "sentiment identitaire national ». Mais aujourd'hui, plus de quinze ans après l'unité, l'Allemagne s'aperçoit soudain de sa nouvelle normalité. Et, de même que le Mondial 1954 («le miracle de Berne ») avait permis à la jeune RFA, composée alors de 11 Länder, d'affirmer aux yeux du monde entier une respectabilité reconquise avant même de recouvrer sa souveraineté d'Etat, le Mondial 2006 permet d'affirmer avec joie et fierté la normalité d'un pays uni et performant.

2 Après tout, "par tradition, le titre de championne du monde de football nous appartient ", ironise M. Matussek, directeur des pages Culture de l'hebdomadaire Der Spiegel. Qu'importe l'issue de ce Mondial, il y a plus important. "Qu'il est cool de ne plus être 
seulement la nation du miracle économique et de voir que notre confiance en nous-mêmes ne se nourrit pas que des taux de croissance économique!», s'exclame avec soulagement l'auteur de cet ouvrage roboratif qui consacre un chapitre à expliquer « en quoi le fait de traverser une crise est bénéfique à la créativité ». Car avec un humour d'une grande finesse, M. Matussek prend le contrepied de tous ces esprits chagrins, qu'ils soient Allemands ou non, qui se complaisent à dresser le portrait d'un pays au «modèle » en déclin. Il ne vise pas tant le discours dominant sur les réformes structurelles; elles restent incontournables pour affronter les défis du XXI siècle. S'il rappelle non sans délectation que l'Allemagne est la $3^{\text {ème }}$ puissance économique mondiale, c'est pour mieux expliquer en quoi consiste la normalité du nouveau patriotisme allemand. "Le patriotisme est une des tendances intrinsèques de la globalisation. Plus le monde s'internationalise, plus se développe le sentiment d'appartenance nationale. C'est un peu comme avec le site de GoogleEarth : vous avez sous les yeux la planète entière, mais vous cherchez avant toute chose à localiser votre propre pays ». Voilà la clef de la nouvelle identité allemande qui se révèle au grand jour à l'occasion du Mondial : une sérénité qui se ressource dans la proximité et ose enfin se souvenir de ses riches racines culturelles.

3 Sous un angle différent, l'ouvrage du directeur des pages Opinions du quotidien économique Handelsblatt, Thomas Hanke, vient corroborer cette analyse. L'Allemagne, explique-t-il, ce pays qu'on croit installé dans l'immobilisme, a profondément changé. "Ses structures économiques et sociales traversent certes une crise - mais il ne s'agit pas d'une crise de stagnation, au contraire, c'est une crise de croissance». Car, affirme-t-il, "ce sentiment d'incertitude qui affecte même les classes moyennes est tout sauf signe d'immobilisme. Il est une manifestation de ces profondes mutations de la société que le monde politique ne parvient pas encore à conceptualiser et qui dès lors l'insécurisent ». L'Allemagne est en train de développer une nouvelle forme de capitalisme : le traditionnel lien banque-industrie (noué sous Bismarck!) se défait, le partenariat social cherche de nouvelles bases, le dialogue institutionnel entre politique, économie et salariat s'est grippé, le 'néocorporatisme' cède aux impératifs d'une concurrence poussée... Le "capitalisme rhénan " n'est plus. Mais la variante qui lui succèdera n'aura rien d'un libéralisme sauvage. "Le contrat social tien bon». L'Allemagne reste foncièrement fidèle au libéralisme organisé et à ces valeurs qui le fondent, dont en premier lieu la solidarité. Or les innombrables débats sur les effets présumés néfastes de la mondialisation masquent la réalité comme l'ampleur de ce changement dans la continuité. A trop vouloir ne considérer la globalisation des activités que sous l'angle de la suppression des emplois et des acquis, on en perd de vue combien l'économie allemande a su se renouveler en l'espace de trente ans. Comment expliquer sinon qu'elle ait pu stabiliser, voire accroître ses parts de marché mondiales? Mais ce processus d'adaptation à un monde en mouvement implique d'y adapter les modes de fonctionnement internes. Déjà, l'Allemagne n'est plus la même... (ib) 